\title{
Human Capital, Local Labor Markets and Regional Integration
}

\author{
Laurence Rioux ${ }^{\bowtie} \quad$ Thierry Verdier $y$ \\ J anuary 2000
}

\begin{abstract}
A bstract
This paper investigates the impact of regional integration on the incentives for local governments to ...nance general human capital in a context of oligopsonistic labor markets, where ..rm's speci..c skills are obtained through speci..c training. General human capital increases both a worker's productivity (productivity exect) and its ability to learn new ..rm’s speci..c skills ( $\ddagger$ exibility exect). For symmetric regions, integration leads to a "race to the top" or to a " race to the bottom" in local public educational policies depending on whether the productivity exect dominates or not the $\ddagger$ exibility exect. The paper discusses also the exects of integration on regional wages, intra-regional wage inequalities and integration between regions dixerent in size or productivity.
\end{abstract}

\section{Introduction}

One of the most important economic fact of the last decades is certainly the increased process of market integration observed between nations and regions. This process, often described as globalization, has been intensively discussed by many social scientists, businessmen or policymakers. Some see in it an opportunity to generate economic wealth and development. Others, on the contrary, make it responsible for the emergence of many social and economic problems in industrialized and developing economies. Most acknowledge the fact that, with its increased mobility of goods and factors of production, market integration imposes new constraints on national governments for the implementation of their local public policies. This aspect is best exempli..ed by the whole line of research on tax competition, factor mobility and the «race to the bottom» argument. This literature generally starts from the idea that regional or national governments have to ..nance a local public good by taxation on a mobile factor (capital or labor). In such a context, each national or regional authority has a strategic interest to reduce its tax rate in order to attract the mobile factor locally. Doing this increases its own tax base at the expense of the other governments. The ..nal result is a sub-optimal level of local public goods with too low a tax rate in each region.

Insee, Timbre F 340, 18 Bd A. Pinard, 75675 Paris Cedex 14, France. E-mail: laurence.rioux@insee.fr. ${ }^{y}$ CERAS, DELTA, and CEPR, 48 Bd J ourdan, 75014 Paris, France. E-mail: verdier@delta.ens.fr. 
While the impact of factor mobility on national tax policies has attracted quite a large amount of attention, much less work has been done on the exect of integration on other public policy dimensions. A crucial one in this respect is human capital and the public supply of education. It is actually hard to deny the fact that in modern economies, education and training are an important source of productivity growth and competitiveness. Individuals acquire a variety of skills in schools, private or public. Firms provide many opportunities to their labor force to obtain ..rm-speci..c skills adapted to speci..c technologies, both through training programs and learning-on-the-job. Governments spend vast amounts of tax-payer money to supply education to their citizen. A natural and important issue, then, is how globalization and regional integration will axect the incentives of individuals to invest in human capital and, most importantly, how it will axect the structure and level of educational policies followed by local governments. Will regional integration be associated with a « race to the bottom» or a «race to the top» for local educational policies? What will be the exects on productivity and wages?

The purpose of this paper is to provide a ..rst attempt to investigate these questions. In order to do this, we build on the recent work of Thisse and Zenou (1995) on local oligopsonistic labor markets in which workers start with dixerent speci..c skills and where, in order to produce within a ..rm, they need to perfectly match the ..rm's skill requirement through training. The more distant is the initial skill of a worker from the ..rm's speci..c requirement, the larger is the training cost. Besides this idea of speci..c human capital as captured above, we follow Becker (1964) and also recognize the existence of a second dimension of human capital, namely general human capital that has three major features. First, it is publicly provided by local governments. Second, it increases a worker's productivity independently from his initial skill location (a productivity exect). Third, it also increases the worker's ability to learn new ..rm speci..c skills, in the sense that the larger the general human capital of a worker, the smaller the training cost for that worker to acquire a new ..rm speci..c skill (a ł exibility exect).

Describing then regional integration by increased mobility of ..rms across regions, we investigate the local governments' incentives to provide general human capital to local workers. We also discuss the implications for regional productivities and wage inequalities within each region. Interestingly, we show that the «race to the bottom» versus « race to the top» debate, so much discussed in the tax competition literature, depends here on the relative strength of the productivity exect versus the $\ddagger$ exibility exect, both exects being associated with general human capital. While the productivity exect has a positive exect on ..rm's pro..t, the $\ddagger$ exibility exect reduces the cost of training born by workers to acquire a ..rm's speci..c skill requirement. In the labor market, this aspect allows workers to be more easily employable by ..rms, increasing therefore competition between rival employers and, consequently, wages which will be oxered.

When the productivity exect dominates the $\ddagger$ exibility exect, ..rms' expected pro..ts in a region are increasing in the level of general human capital of the population. Hence the region which is better endowed with general education is also more successful at attracting ..rms and employers in its local labor market. This generates an incentive for each regional government to increase strategically its level of general human capital in order to attract ..rms locally. The equilibrium result is a higher level of general education after integration than before, 
higher local wages and a decrease in intra-regional inequalities. The «race to the top» argument applies. On the contrary, when the łexibility exect outweighs the productivity exect, then all results are reversed. Firms prefer to be localized in the region less endowed with general human capital, as they enjoy a higher monopsonic power because of the workers' relative in $\ddagger$ exibility. Consequently, in order to attract these ..rms, local governments have a tendency to reduce their provision of general human capital. Competition between regions results in a lower equilibrium level of general education in each region, associated with lower wages and an higher intra-regional inequalities. The «race to the bottom» argument prevails in this case.

The plan of the paper is the following. The following section presents the oligopsonistic labor market model à la Thisse and Zenou with speci..c and general human capital for a given region in autarky. Section 3 considers the case of integration between two symmetric regions and presents several comparative statics on the equilibrium level of general human capital provided by local governments. Section 4 discusses the case of asymmetric regions in population size or productivity level. Finally section 5 concludes. All proofs are relegated to an appendix.

\section{The model}

Consider an economy formed by two regions $i(i=A ; B)$ : Each region $i$ is composed of $n_{i}$..rms and a continuum of workers. Firms produce an homogeneous good sold on a competitive market with a price normalized to 1 . The total number of ..rms is ..xed and given by $\mathrm{N}=\mathrm{n}_{\mathrm{A}}+\mathrm{n}_{\mathrm{B}}$ :

We suppose that there is no worker mobility between the two regions. We will investigate sequentially the case in which ..rms cannot move between regions (No Integration) and the case with interregional ..rms' mobility (Integration).

\subsection{General and speci..c human capital and production technology}

Following Becker (1964), we consider that human capital has two dimensions: a vertical dimension (general human capital) and a horizontal dimension (speci..c human capital). General human capital is publicly provided by the regional government ${ }^{1}$. Hence all workers, after school in region $\mathrm{i}$; are endowed with the same level $\mathrm{g}_{\text {. }}$ In each region however, individuals dixer in their speci..c skills. There is no a priori superiority or inferiority among these skills as they only rełect dixerent ex ante speci..cities in the educational background of a worker (for example, workers may have a degree in engineering but in dixerent ...elds).

Formally, following Thisse and Zenou (1995), it is assumed that, in region i; speci..c skills are uniformly distributed with density $\phi_{i}$ on a circle $C_{i}$ of length $L_{i}$ where $C_{i}$ represents is the skill space and $L_{i}$ rełects the degree of diversity in workers' speci..c skills. As workers

\footnotetext{
${ }^{1}$ We suppose that general human capital is not ..nanced by the central government nor privately by agents. This assumption, though presented here in an extreme form, seems to be quite reasonable from an empirical point of view. As a matter of fact, more than 80 per cent of education expenditures, in most industrialized countries is ..nanced publicly (OECD (1998)). M oreover, in many countries public education is regionally funded (Germany, Spain, The United States and Canada).
} 
are supposed to supply inelastically 1 unit of labor, $\phi_{i} L_{i}$ is the total labor force in region i. 2

In region $\mathrm{i}$, we consider that each representative ...rm $\mathrm{j}$ is endowed with a technology of production which necessitates a given speci...c skill $x_{j}^{i}$ in the same space $C_{i}$ : M oreover these ..rm speci...c skill requirements are distributed symmetrically on the circle $C_{i}$ and given by $x_{j}^{i}=\frac{(j i 1) L_{i}}{n_{i}}, 8 j=1 ; \cdots ; n_{i}:{ }^{3}$

In order to produce within a ..rm, a worker needs to perfectly match the ..rm's skill requirement ${ }^{4}$. Since workers' speci..c skills are uniformly distributed on the circle $C_{i}$, workers need therefore speci..c training to match the ..rm's technology $x_{j}^{i}$ : Now, the more distant the skill of a worker from the ..rm's speci..c requirement, the larger the training cost. M ore precisely, we consider as Thisse and Zenou $(1995,1996)$, that the training cost is given by the following linear function $s^{-} x_{i} x_{j}^{j^{-}}$of the distance between the worker's skill $x$ and the ..rm's requirement skill $x_{j}^{i}$ : At the same time, one may expect that the larger the general human capital of a worker, the more łexible is this worker in terms of learning ${ }^{5}$. And therefore the easier it is to acquire the skill requirement of the ..rm. Formally, this means that $s$ depends on the level of general human capital $\mathrm{g}$ of a worker. Reł ecting our assumption of learning łexibility associated with general human capital, the cost of training per unit of distance $s(g)$ is a decreasing convex function of $g\left(\right.$ i.e. $s^{0}(:)<0$ and $\left.s^{\infty}(:)>0\right)$.

Once matched to the ..rm's required speci..c skill, a worker can start producing within the ..rm. We consider furthermore that the larger is his level of general human capital, the higher is his productivity. More precisely, the output produced by a ..rm of region $\mathrm{i}$ employing ' workers (having skill $x_{j}^{i}$ after training) is given by a standard increasing concave production function $F_{i}\left(g_{i}\right)$; with $F_{i}^{0}\left(g^{\prime}\right)>0$ and $F_{i}^{\infty}\left(g_{i}\right)<0$.

Note already that a higher level of general human capital in region i has two exects on ..rms' pro.ts. First there is a productivity exect as all workers in this region are more productive, once they are matched to the ..rm's technology. On the other hand, there is also a $\ddagger$ exibility exect associated to the fact that workers better endowed with general human capital can learn faster new speci..c skills. It is clear that the productivity exect has a positive exect on ..rm's pro..t. On the other hand, the $\ddagger$ exibility exect reduces the cost of training born by workers to acquire a ..rm's speci..c skill requirement. In the labor market, this aspect allows workers to be more easily employable, increasing therefore competition between rival employers and consequently equilibrium wages. This in turn has a negative impact on ..rms' pro..ts.

\footnotetext{
${ }^{2} \mathrm{~T}$ his model is related to the specialization model of $\mathrm{Kim}$ (1989) in which agents can choose between general education and specialized education. Specialized education provides a higher productivity on a limited range of speci..c skills while general education allows individuals to shift more easily between speci..c skills and have a higher probability of employment. Kim shows that an increase in the size of the labor market is associated with an increase in specialized education by workers.

${ }^{3}$ As shown by Stevens (1994), ..rms, in order to increase their market power, have incentives to choose technologies of production requiring speci..c training that protects their "location" against rival employers. A Iso, by analogy with results in the literature on spatially dixerentiated products, a symmetric con..guration of technologies is likely to be an equilibrium outcome of a game in which ..rms choose in a ..rst stage their technologies and then, in a second stage, their wages (E conomides (1989), K ats (1995)).

${ }^{4} \mathrm{~T}$ he technology of production is of an extreme O-R ing type (K remer 1993).

${ }^{5}$ Think of one component of general human capital as being "learning to learn" , (ie. developing an ability to learn better).
} 
We assume that, before signing an employment contract, ..rms cannot observe the worker's type, while workers observe ..rms' job requirement. A fter hiring, the worker's type is revealed to the ..rm and training is made in the ..rm. It is assumed that, in each region $\mathrm{i}$, the cost of speci..c training is shared between a worker and the ..rm hiring him with a

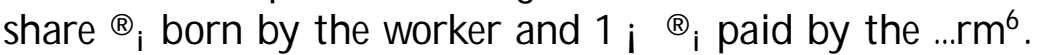

We consider that the local government takes the decision on the amount of general human capital $\mathrm{g}$ provided in the region?

\subsection{Functioning of the local labor market}

The working of the labor market in each region follows closely Thisse and Zénou (1995; 1996). Once $g_{i}$ is provided by the local government, ..rms $\mathrm{j}=1 ;:: ; \mathrm{n}_{\mathrm{i}}$ in region $\mathrm{i}$ choose simultaneously their wage level $f w_{j}^{j} g_{j} 2\left(1 ; n_{i}\right)$ oxered to all workers. Each ..rm proposes a single wage as, ..rst, the initial speci..c skill of a worker is not known to the ..rm before signing the employment contract, and second, because all workers, from the-point of view of the ..rm, are alike after training. The net wage oxered is then $w_{i}^{i} \otimes_{i} s(g){ }^{-} x_{i} x_{j}^{i^{-}}$. A gents choose to sign a contract and work for the ..rm oxering them the highest net wage, provided that this wage is higher than the reservation wage which is normalized to 0 .

We can then characterize easily the labor market equilibrium for a region with $n_{i} . . r m s^{8}$. Denote $j$ the representative ..rm. Given wages $w_{j_{i} 1}^{i}$ and $w_{j+1}^{i}$ oxered by the adjacent ..rms, it is straightforward to see that ..rm j's labor pool is composed of two sub-segments whose outside boundaries are given by the marginal workers $x_{j}^{i}$ and $y_{j}^{i}$ : these workers are indixerent between being hired, on the one hand, by ...rms $j \mathrm{i} 1$ and $j$, and, on the other hand, by .rms $\mathrm{j}$ and $\mathrm{j}+1$. More precisely, $\mathrm{x}_{\mathrm{j}}^{\mathrm{i}}$ and $\mathrm{y}_{\mathrm{j}}^{\mathrm{i}}$ are given by:

$$
w_{j}^{i} i \circledast s(g)\left(x_{j}^{i} x_{j}^{i}\right)=w_{j i}^{i} i \quad \circledast s(g)\left(x_{j}^{i} i x_{j i 1}^{i}\right)
$$

and

which gives

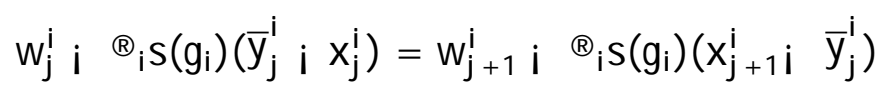

$$
\begin{aligned}
& \stackrel{8}{<} x_{j}^{i}=\frac{w_{j_{i} 1}^{i} w_{j}^{i}+\Theta_{S}\left(g_{1}\right)\left[x_{j}^{i}+x_{j_{i}}^{i}\right]}{2 \Theta_{s}\left(g_{i}\right)} \\
& : y_{j}^{i}=\frac{w_{j}^{j} i w_{j+1}^{j}+\Theta_{S} s\left(g_{i}\right)\left[x_{j}+x_{j+1}^{j}\right]}{2 \Theta_{S}\left(g_{i}\right)}
\end{aligned}
$$

Firm $j$ attracts and hires all woskers who belong to the pool $\left[x_{j}^{i} ; y_{j}^{i}\right]$ : Therefore employment for ..rm j is given by ${ }^{\prime} j=\phi_{i} y_{j}^{i} i \quad x_{j}^{i}$ : Given this and the fact that the .rm pays a

\footnotetext{
${ }^{6} \mathrm{~T}$ he case $\mathbb{R}=1$ is close to the situation of the US in which workers ..nance entirely their speci..c training. On the contrary, $\otimes=0$ approximates the german case in which education is mainly ..nanced by ..rms through a system of training and apprenticeship.

${ }^{7}$ To simplify, we suppose that the legislation on the share of training costs is ..xed to a certain value $\mathbb{B}=\mathbb{R}$. The government could also choose endogenously the legislation on $\mathbb{Q}$ : As in Thisse and Zenou (1995), it is easy to show that the government has an incentive to pick ${ }_{\text {\& }}$ close to zero in order to maximize net expected wages in a region.

${ }^{8}$ We consider only sets of parameters that ensures full employment.
} 
fraction $1 \mathrm{i} \otimes$ of the training costs, we can write pro..ts as:

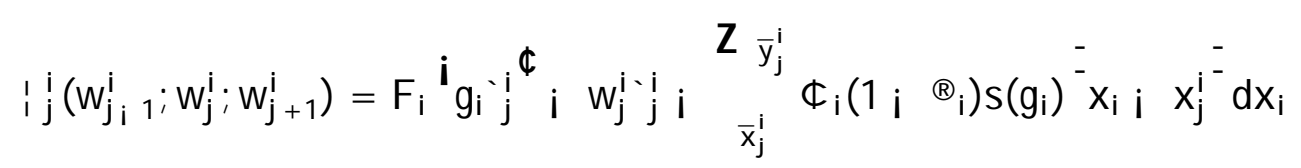

which gives:

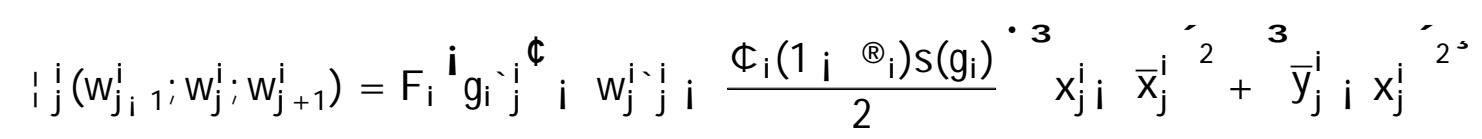

The pro..t function is continuous in ${ }^{i} w_{j i}^{i} ; w_{j}^{j} ; w_{j+1}^{i}{ }^{\phi}$ and concave in $w_{j}^{i}$. Firm $j$ chooses its wage $w_{j}^{i}$ to maximize ${ }_{j}^{j}\left(w_{j i}^{i} ; w_{j}^{i} ; w_{j+1}^{i}\right) ;$ taking as given $w_{j i 1}^{i}$ and $w_{j+1}^{j}$. The ..rst order condition of (2:3) writes as:

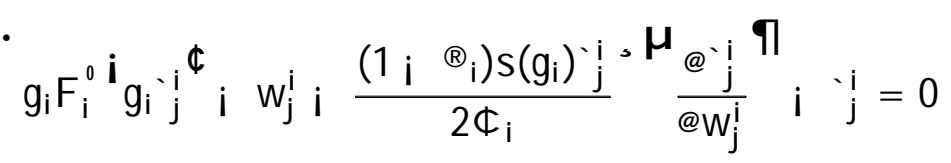

with $\frac{\varrho_{j}^{j}}{\Theta_{j}^{j}}=\frac{q_{i}}{\Theta s\left(g_{i}\right)}$. In a symmetric $N$ ash Equilibrium, $w_{j_{i} 1}^{i}=w_{j}^{j}=w_{j+1}^{i}, x_{j}^{i}=\frac{\left[x_{j}^{j}+x_{i 1}^{j}\right]}{2}$ and $y_{j}^{i}=\frac{\left[x_{j}^{i}+x_{j+1}^{i}\right]}{2}$ : Therefore

$$
i_{i}^{\infty}=\frac{\phi_{i} L_{i}}{n_{i}}
$$

Using then equation (2:4), one gets the gross equilibrium wage and pro.ts $a s^{9}$ :

$$
\begin{aligned}
& w_{i}^{\alpha}=g_{i} F_{i}^{0}\left(g_{i}^{\prime a}{ }_{i}^{\prime}\right) i \frac{(1+\mathbb{Q}) s(g)_{i}^{\prime o}}{2 \phi_{i}}
\end{aligned}
$$

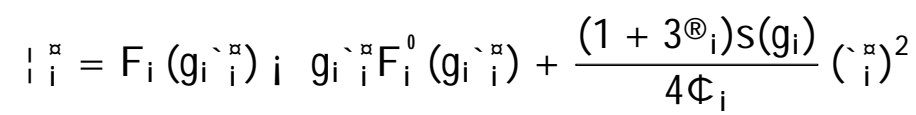

The previous results can be summarized usefully in the following proposition:

Proposition 1. Under the condition $g F_{i}^{0} g_{i} \frac{\phi_{i} L_{i}}{n_{i}}>\frac{(1+\Theta) s\left(g_{i}\right) L_{i}}{2 n_{i}}$; there exists a unique symmetric Nash Equilibrium in wages in region $i$ in which each ..rm employs ${ }^{\wedge}=\frac{\Phi_{i} L_{i}}{n_{i}}$ workers, and equilibrium wages and pro..ts are given by equations (2:6) and (2:7). The net expected wage is $W_{i_{\text {net }}}^{q}=W_{i}^{a} i \frac{Q_{S}\left(g_{i}\right)_{i}^{p}}{4 \phi_{i}}$ and the intra-regional wage dispersion is given by $V_{i}^{\alpha}=\frac{1}{3} \frac{\Theta s\left(g_{i}\right)_{i}^{\prime \prime}}{2 \phi_{i}}$.

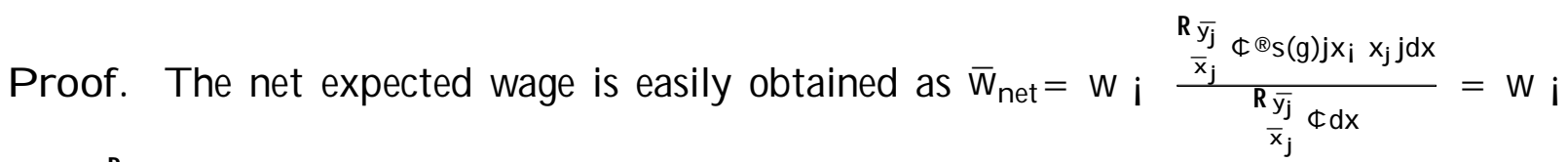
$\frac{\Phi{ }^{B s}(g){ }_{\bar{y}_{j}}^{{ }^{R} \bar{y}_{j}} j x_{i} x_{j} j d x}{\Phi\left(y_{j} i \bar{x}_{j}\right)}$ : But ${ }^{i} \bar{y}_{j} i \quad x_{j}{ }^{\Phi}=\frac{2}{\Phi}$.

\footnotetext{
${ }^{9} \mathrm{~T}_{3}$ he necessary and suф cient condition on parameters to get full employment is easily obtained as $g_{i} F_{i}^{0} \quad g_{i} \frac{\phi_{i} L_{i}}{n_{i}} \quad$ i $\frac{\left(1+\Theta_{1}\right) s\left(g_{i}\right) L_{i}}{2 n_{i}}>0:$
} 
Substituting $\bar{y}_{j}$ i $x_{j}$, we get $w_{n e t}=w_{i} \frac{{ }_{s}(g)^{\prime}}{4 \phi}$.

To compute the jntra-regional dispersion, let $j x_{i} x_{j} j=z_{j}$.

Then $\mathrm{W}_{\mathrm{j}} \mathrm{i} \mathrm{W}_{\text {net }}=\mathrm{BS}_{\mathrm{S}}(\mathrm{g}) \frac{\overline{4}}{4 \mathrm{q}} \mathrm{i} \mathrm{z}_{\mathrm{j}}$ :

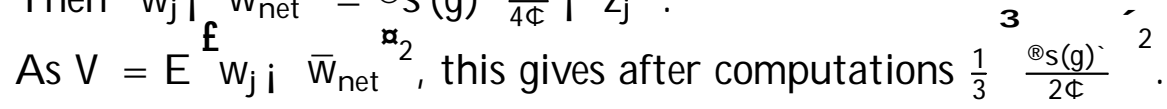

From proposition 1, it is clear that the equilibrium wage and the net wage are decreasing in the population density $\phi_{i}$ and the size of the regional labor force $L_{i}$ and increasing in the number of ..rms $n_{i}$ located in the region. As explained by Thisse and Zenou (1995, 1996), the decreasing relationship between the size of the labor force and the equilibrium wage comes from the fact that the monopsonic power of employers (..rms) increases with the number of workers.

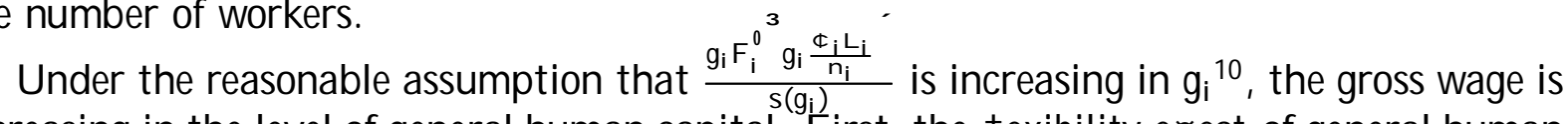
increasing in the level of general human capital. ${ }^{\mathrm{F}} \mathrm{First}$, the $\neq$ exibility exect of general human capital reduces the costs of training on the speci...c skill requirement of the ..rm. Also it decreases the monopsonic power of employers in the labor market, as workers are more «mobile» between ..rms speci..c skills. This increases wages oxered in equilibrium. Second, because of the productivity exect, general human capital also increases the productivity of workers inside ..rms after training. This again tends to increase their wages.

Finally, note that the equilibrium wage is decreasing in $\circledast$ the share of training ..nanced

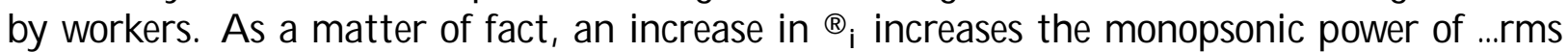
and therefore reduces the gross equilibrium wage oxered by ..rms. The net expected wage decreases further as training costs paid by workers get larger.

The impact of the various parameters on equilibrium pro..ts mirrors the previous discussion on wages and gives immediately that equilibrium pro..ts are increasing in $\phi_{i} ; \frac{L_{i}}{n_{i}}$ and @:

The exect of the level of general human capital on pro..ts is more ambiguous. From

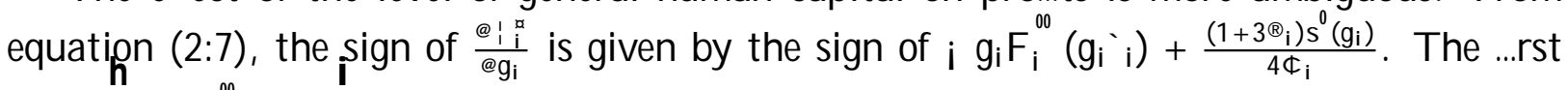
term, $\quad g_{i} F_{i}^{\infty}\left(g_{i}\right)$; is positive and reł ects the productivity exect of general human capital on ..rms pro.tability. As trained workers are more productive when they are endowed with more general hhuman capital, part of the productivity gains are captured by ..rms. The second term, $\frac{(1+3 \otimes) s^{0}(g)}{4 \phi_{i}}$; however is negative and represents the $\ddagger$ exibility exect of general human capital. As the labor force has more general education, it is also more $\ddagger$ exible and therefore more «mobile» potentially between rival employers, increasing competition between ..rms in the labor market. Equilibrium wages are increased and ..rms' pro..ts are reduced. Clearly, the total exect of general human capital on the ..rms' pro..tability depends on which exect dominates. When the productivity exect outweighs the $\ddagger$ exibility exect, then ..rms' pro..ts are higher when the population is better endowed in general human capital. Otherwise, we get the opposite result.

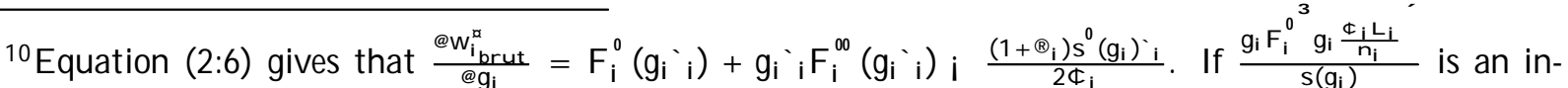

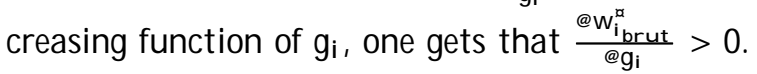




\section{Integration between two identical regions}

In this section, we consider how the educational policy of two identical regions is axected when ..rms are allowed to move between regions (i.e. regional integration). Restricting ourselves to symmetric regions greatly simpli..es the analysis and allows us to isolate the «pure» exects of regional integration. In section 4, we discuss in a speci... example, the marginal impact of asymmetry of regions on local educational policy choices.

Regions $\mathrm{A}$ and $\mathrm{B}$ are identical. Hence $\mathrm{F}_{\mathrm{A}}(:)=\mathrm{F}_{\mathrm{B}}(:)=\mathrm{F}(:)$ and $\mathbb{B}_{\mathrm{A}}=\mathbb{B}_{\mathrm{B}}=\mathbb{B}_{\text {, }}$ $L_{A}=L_{B}=L$ and $\phi_{A}=\phi_{B}=\phi$ :

In order to determine the impact of regional integration on local educational policy, we will discuss the policy chosen by each region, ..rst, when there is no integration and, next, when there is inter-regional mobility of ..rms. We suppose that local governments want to maximize the net expected wage of their citizen minus the cost of funding general human capital ${ }^{11}$. Formally the objective function of a regional government is given by:

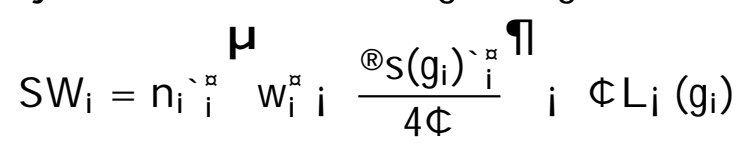

when $n_{i}$..rms are localized in region $i$ and each of them employs ${ }_{i}^{\alpha}=\frac{\phi L}{n_{i}}$ workers, each

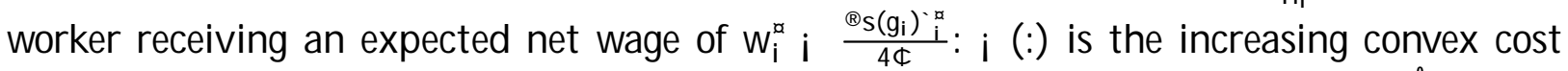
function to supply a level of general human capital $g$ to any individual with $\mathrm{i}^{\circ}(:)>0$ and $\mathrm{i}^{\infty}(:)>0$. Note that the general human capital formation is supposed to be ...nanced by lump sum taxes on workers. Therefore this type of ..nancing does not give rise to the standard ..scal competition between regions when there is inter-regional mobility.

\subsection{Educational policy with no regional integration}

Consider ..rst the case in which ..rms cannot move between regions. Each region is then completely independent from the other. As they are assumed identical, $n_{A}=n_{B}=\frac{N}{2}$ : Then each ...rm in region i employs ${ }^{`}=\frac{2 t L}{N}$ workers.

The maximization program of the local government of region $\mathrm{i}$ writes as:

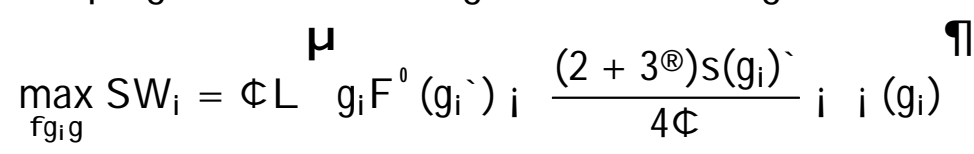

The ..rst order condition gives:

$$
F^{0}\left(g^{\prime}\right)+g^{\prime} F^{\infty}\left(g^{\prime}\right) \text { i } \frac{\left(2+3 ब s^{0}(g)^{\prime}\right.}{4 \phi} ; i^{0}(g)=0
$$

The second order condition is satis..ed when $s\left(g_{i}\right)$ and $i(g)$ are convex enough. Denote by $g_{c}^{a x}$ the solution of equation (3:3). Dixerentiation of this equation provides then the following result:

\footnotetext{
${ }^{11}$ T his objective function for the local governements can be justi..ed by a political economy argument if one expects workers to be the decisive political agents in a given region.
} 
Proposition 2. The optimal level of general human capital $g_{c}^{a}$ provided in each region

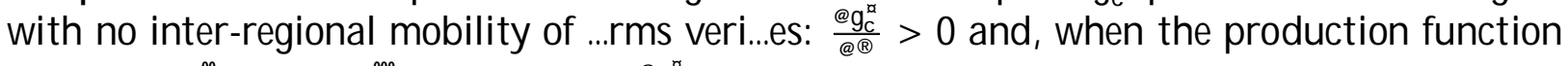

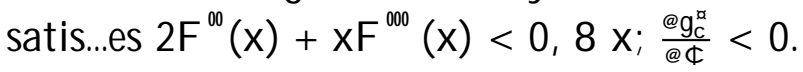

Proof.

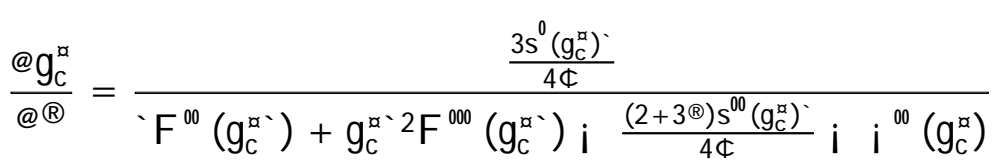

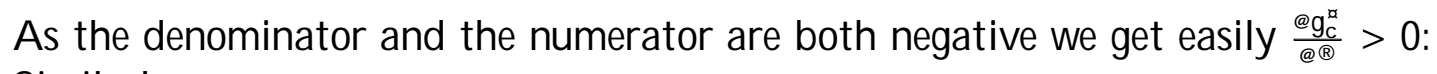

Similarly

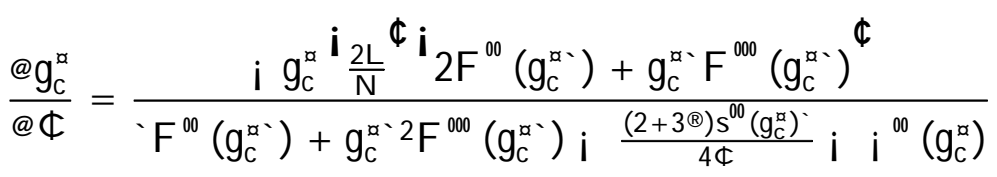

The denominator is negative while the numerator is positive when $2 \mathrm{~F}^{\infty}(\mathrm{x})+\mathrm{xF}^{\infty}(\mathrm{x})<0$ : Hence $\frac{\mathrm{Q}_{\mathrm{C}}^{\mathrm{a}}}{\mathrm{Q}_{\mathrm{a}}}<0$ :

The ..rst comparative statics of proposition 2 gives that the optimal level of general human capital $g_{c}^{\alpha}$ increases with the share ${ }^{\circledR}$ of the training costs paid by workers. The intuition for this is the following. When workers pay a higher share ${ }^{\circledR}$ of the training costs, the monopsonic power of ..rms is increased. Consequently, ..rms are able to propose lower wages. In order to mitigate this exect on wages, the optimal level of general human capital has to be increased. First because this reduces the part of the training cost supported by workers by the $\ddagger$ exibility exect. Second, because the productivity exect makes workers more productive once they have been trained to the skill requirement of a ...rm. ${ }^{12}$

The second part of proposition 2 shows that the optimal level of general human capital $g_{c}^{a}$ decreases with the regional population density $₫$ under a reasonable technical assumption (which is for instance satis..ed by a quadratic production technology). The reason is that, as the population gets larger, it becomes more costly to provide a given level of general human capital to each individual. Therefore $g_{c}^{a}$ has to decrease. The consequence of this is the fact the net wage received by workers is also smaller for two reasons. First the monopsonic power of ..rms increases with $\phi$ : Second, as they depend positively on the level of general human capital provided by the government, wages will also be negatively axected by a decrease in ge:

\subsection{Educational policy with regional integration}

Consider now that ..rms can choose the region in which they want to produce. The timing of the game is then the following. In a ..rst stage, each local government in region $\mathrm{i}$; $8 \mathrm{i}=\mathrm{fA} ; \mathrm{Bg}$; chooses a level of general human capital publicly provided $g_{1}^{\mathrm{a}}$ to maximize its objective function (net expected wages minus the cost of general human capital provision) taking as given the choice of the other regional government. In a second stage, ..rms decide

\footnotetext{
${ }^{12}$ Data from Regards sur l'éducation: Les indicateurs (OCDE) suggest that countries in which ..rms pay a higher share of speci..c training, also tend to have a smaller share of public spendings to general education. For instance, Germany where ..rms pay a large share of speci..c training, allocates 10 per cent of its public spendings to education. On the other hand, in the US where ..rms do not contribute much to workers' speci..c training costs, education represents $14 \%$ of public spendings.
} 
their regional localisation according to the highest pro..t they expect to get in one or the other region. In each region $\mathrm{i}_{1} . . \mathrm{rms}$ then locate symmetrically in the characteristic space $\mathrm{C}_{\mathrm{i}}$ : In the third stage, they choose wages in the local labor market in a Nash fashion. Finally, workers get trained and production is realized.

The third stage describes the labor market equilibrium for a ..xed number of regional ..rms $n_{i}$ and has been already solved in the previous section. Mobility of ..rms between the two regions implies that regional pro..ts have to be equalized at the equilibrium. This generates a division of the total number of ..rms $\mathrm{N}$ between the two regions. The program of the local government of region $\mathrm{i}$ in the ..rst stage is given by:

$$
\begin{aligned}
& \left.\max _{f g_{i} g} S W_{i}=\phi L \quad g_{i} F^{0}\left(g_{i}{ }_{i}\right) i \frac{(2+3 \Theta) s\left(g_{i}\right)_{i}}{4 \phi} i i_{i}\right)^{\text {व }} \\
& \text { under the constraint of pro..ts equality, }
\end{aligned}
$$

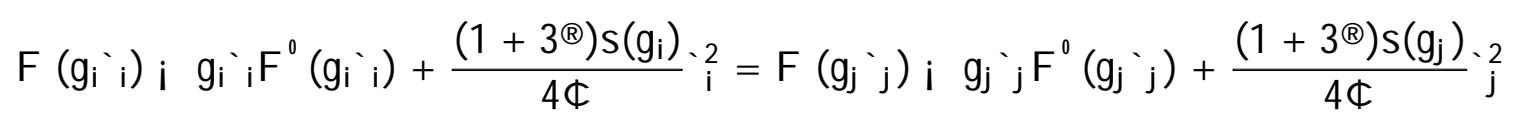

We consider the symmetric Nash equilibria in local general human capital policies. As both governments in such a symmetric equilibrium choose the same level of general human capital, the two regions oxer the same expected pro..ts to ..rms and consequently have also the same number of ..rms, $\mathrm{n}=\frac{\mathrm{N}}{2}$. In each region, each ..rm hires the same number of workers, ${ }^{\prime}=\frac{2 \phi \mathrm{L}}{\mathrm{N}}$. Using the ..rst order condition of the optimization program of government $i$ and substituting the symmetry condition $g=g$; we get the following condition characterizing the symmetric Nash equilibrium $g^{a x}=g_{0}^{a x}=g^{a x}$ :

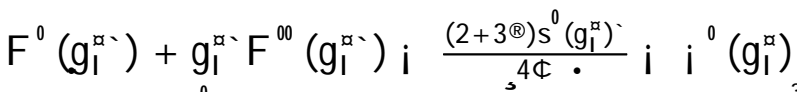

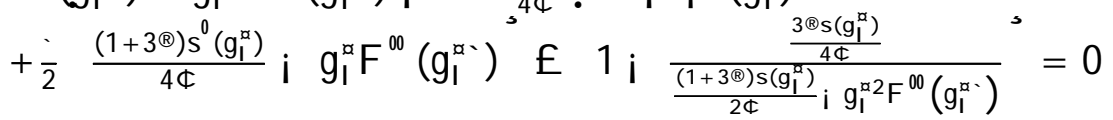

Proposition 3. When $\mathrm{i}(:)$ is suф ciently convex, there exists a unique symmetric Nash equilibrium in general human capital between the two regions where $g^{a}=g_{j}^{a}=g^{a}$ : $M$ oreover $\frac{Q^{\prime \prime}}{\varrho^{\prime \prime}}>0$ :

Proof. See appendix.

The intuition behind the comparative statics result is easy to understand. When the share of training costs ${ }^{\circledR}$ paid by workers increases in one region $\mathrm{i}$, then the monopsonic power of ..rms and expected pro..ts in that region increase. Consequently, ..rms are more likely to get localized in region $\mathrm{i}$ everything else being equal. This allows the local government of that region increasing the level of general human capital to mitigate the negative impact of a higher ${ }^{\circledR}$ on wages, even though this increase potentially has a negative impact on regional ..rms' pro..ts through the $\ddagger$ exibility exect. 


\subsection{The exect of regional integration on local educational policies}

In this section, we compare the optimal choice of general human capital with and without regional integration. As we may expect, this comparison will depend crucially on the relative importance of the productivity exect and the $\ddagger$ exibility exect on ..rms pro..ts. It is thus useful to rewrite the equilibrium equations describing $g_{c}^{a}$ and $g_{r}^{a}$, in a way which isolates these two exects. More precisely

$$
\begin{aligned}
& F^{0}\left(g_{c}^{a ’}\right) \text { i } \frac{s^{0}\left(g_{c}^{a}\right)^{\prime}}{4 \phi} \text { i i }{ }^{0}\left(g_{c}^{a}\right) \text {; }{ }^{\prime} B\left(g_{c}^{\alpha}\right)=0
\end{aligned}
$$

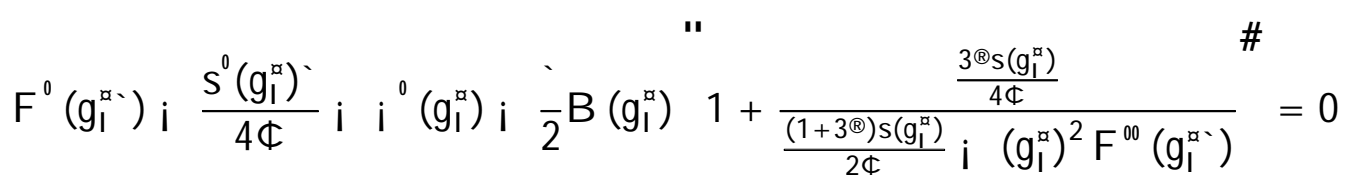

$$
\begin{aligned}
& \text { h }{ }^{0}(i
\end{aligned}
$$

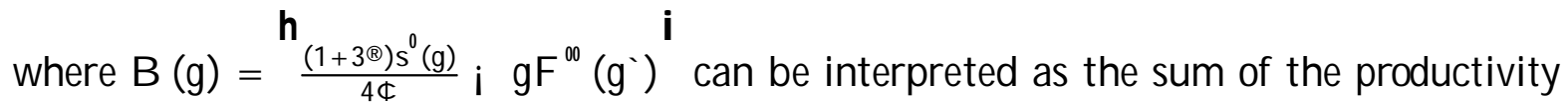
exect, i $\mathrm{gF}^{\infty}\left(\mathrm{g}^{\prime}\right)>0$; and the $\ddagger$ exibility exect, $\frac{(1+3 \otimes) \mathrm{s}^{\circ}(g)}{4 \mathrm{q}}<0$; and ${ }^{`}=\frac{24 \mathrm{~L}}{\mathrm{~N}}$.

The following proposition gives the conditions under which regional integration axects positively or negatively the level of general human capital provided by the local government.

Proposition 4. Let $g$ such that $\frac{\mathrm{gF}^{0}\left(\mathrm{~g}^{\prime}\right)}{\mathrm{s}^{\circ}(\mathrm{g})}=\frac{1+3 \Theta}{4 \Phi}$.

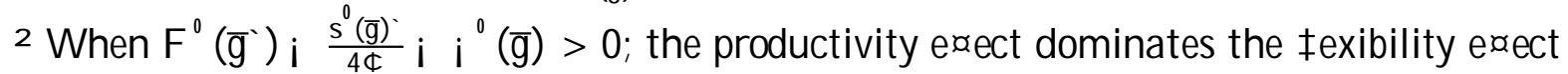
and regional integration implies an increase in the level of general education provided by local governments (i.e. $g_{c}^{a}<g_{i}^{a}$ ). This is associated with an increase in regional wages and a decrease in intra-regional inequalities.

${ }^{2}$ When $F^{0}\left(g^{\prime}\right)$ i $\frac{s^{0}(g)^{\prime}}{4 \phi} i i^{0}(g)<0$; the $\ddagger$ exibility exect dominates the productivity exect and regional integration implies a decrease in the level of general education provided by local governments (i.e. $g_{c}^{a}>g^{a}$ ). This is associated with a decrease in regional wages and an increase in intra-regional inequalities.

Proof. See appendix.

Proposition 4 shows precisely how the impact of regional integration on local educational policies depends on the relative importance of the productivity exect and the $\ddagger$ exibility exect associated with general human capital.

Clearly when the productivity exect dominates the $\ddagger$ exibility exect, ..rms' expected profits in a region are increasing in the level of general human capital of the population. Hence the region which is better endowed with general education is also more successful at attracting ..rms and employers in its local labor market. This generates an incentive for each regional government to increase strategically its level of general human capital in order to attract ..rms locally. The equilibrium result is a higher level of general education after integration than before. The bene..ts of this is also higher local wages and net wages and a decrease in intra-regional inequalities.

On the other hand when the $\ddagger$ exibility exect outweighs the productivity exect, then all the results are reversed. Firms prefer to be in the local labor market which is less endowed 
with general human capital, as they enjoy a higher monopsonic power because of the relative inłexibility of workers in that region. Consequently, in order to attract these ..rms, local governments have a tendency to reduce their provision of general human capital. The competition between regions in this respect results in a lower equilibrium level of general education in each region, associated with lower wages and an increase in intra-regional inequalities.

Without a more precise speci..cation of the technology of production, it is dic cult to get conditions on fundamental parameters ensuring a positive exect of regional integration on education, wages and inequalities. Nevertheless, we may get interesting comparative statics on g; the level of general human capital at which the productivity exect and the $\ddagger$ exibility exect compensate each other. More precisely, simple computations show:

Proposition 5.

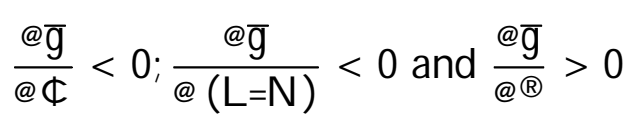

$g$ is a decreasing function of the population density $₫$ and the size of the labor pool $\frac{2 \mathrm{~L}}{\mathrm{~N}}$ of ..rms. Consequently, the set of values of general human capital for which the productivity exect dominates the $\neq$ exibility exect gets larger with $\phi$ and $\frac{L}{N}$ : Inversely $g$ is increasing with $\circledast$ the share of the training costs which is paid by workers. Thus, the more workers contribute to the ..nancing of speci... capital training, the smaller is the set of values of general human capital for which the productivity exect outweighs the $\ddagger$ exibility exect.

\subsection{A quadratic example}

In order to have a more precise idea of the circumstances under which regional integration has a positive or a negative impact on local educational choices, let us consider the example of a quadratic production function:

$$
F\left(g^{\prime}\right)=a_{i} \frac{b}{2} g^{\prime} g^{\prime}
$$

Let us also denote $h(g)=\frac{i g}{s^{\circ}(g)}$ : Given that $s(:)$ is decreasing convex, it is easy to see that $h(:)$ is increasing and therefore that $h^{i}{ }^{1}(:)$ is also increasing.

$g$ is then solution of

$$
\frac{i g}{s^{0}(g)}=\frac{1+3 \circledR}{4 \pitchfork b}
$$

or

$$
g=h^{i}{ }^{\mu} \frac{1+3 \otimes^{q}}{4 \phi b}
$$

The condition for regional integration to be associated with an increase in the local provision of general education is then:

$$
a_{i} \frac{2 \phi L}{N} \log i \frac{s^{0}(g) L}{2 N} i_{i}{ }^{0}(g)>0:
$$


Substituting g provides a condition on the structural parameters $\mathbb{R} \notin$ and $\frac{L}{N}$ :

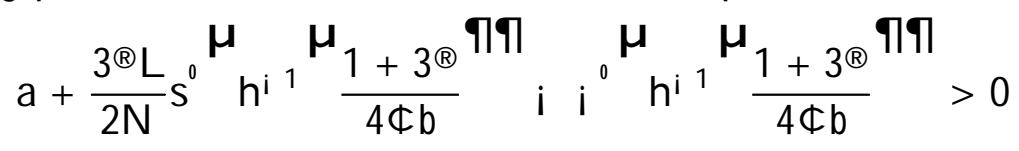

This condition is more likely to be satis..ed the smaller is the labor pool $\frac{2 L}{N}$ of each ..rm. More precisely, it is easy to see that there is a threshold value of $\frac{L}{N}$ below which $(3: 8)$ is satis...ed. Hence, for a given total number of ..rms $\mathrm{N}$; the larger the size of the two regions $L$, the less likely will regional integration be associated with an increase in local public education. (3:8) is also more easily satis..ed when the density $\$$ is high. Hence the less densely populated are the two regions, the less likely is regional integration associated with an increase in general human capital publicly provided. The et ciency of the ..rms' technology of production (as captured by the productivity parameters $a$ and b) also plays a role. As a matter of fact, the higher is $a$ and the smaller is $b$, that is the more ed cient is the technology, the easier is condition (3:8) satis..ed. Finally, condition (3:8) depends on the way training costs are shared between workers and ..rms. When workers contribute more to the ..nancing of training costs, regional integration is more likely to lead to a decrease in the investment in general human capital.

\section{Integration between two asymmetric regions}

Until now we have considered the case of integration between identical regions. This allowed us isolating the "pure» exects of ..rms mobility on the incentives for local governments to provide general human capital. It may be of course also interesting to analyze the case of integration of asymmetric regions. In particular, one may want to discuss what happens when two regions of dixerent size get integrated? Do they both bene.t or loose? Which region (the large one or the small one) bene..ts most from the integration?

Doing however a full analysis of the problem of integration of two asymmetric regions is diф cult as one cannot anymore compute explicitly the $\mathrm{Nash}$ asymmetric equilibrium between the two local governments ${ }^{13}$. Still, restricting ourselves to the quadratic example, we are able to get some insights on the impact of integration on slightly asymmetric integration. Consider then again quadratic production functions of the type

$$
F_{i}\left(g_{i}\right)=a_{i} i \frac{b}{2} g_{i} \grave{g}_{i}
$$

and quadratic training functions $s_{i}(:)$ (i.e. $s_{i}^{\infty 0}(:)=0$ ).

We will also concentrate on two sources of asymmetries, namely size $L_{A} \in L_{B}$ and productivity $\mathrm{a}_{\mathrm{A}} \sigma \mathrm{a}_{\mathrm{B}}$ : Therefore we consider in the rest of this section that $\mathrm{s}_{\mathrm{i}}(:)$ and $\mathrm{i}_{\mathrm{i}}(:)$ are the same in the two regions. Also $\phi_{A}=\phi_{B}=\phi$ and $b_{A}=b_{B}=b$. Finally we will consider the case in which $\mathbb{B}_{A}=\mathbb{B}_{B}={ }^{B}$ is close to 0 ; that is the case in which most of

\footnotetext{
${ }^{13}$ The literature on the exects of regional integration in the asymmetric case is relatively sparse and deals exclusively with the issue of ..scal competition. See Bucovetsky [1991] for an analysis with quadratic production functions and $W$ ilson [1991] for the general case. These analyses suggest that ..scal competition tends to favor the small region.
} 
the training cost is paid by ...rms ${ }^{14}$. In equilibrium in each regional labor market $\mathrm{i}$, we have $\mathrm{I}_{\mathrm{i}}=\frac{\Phi \mathrm{L}_{\mathrm{i}}}{\mathrm{n}_{\mathrm{i}}}$

The local government of region i chooses then its level of general human capital, $g_{i}^{a}$; which maximizes the welfare of the workers in its region. Hence

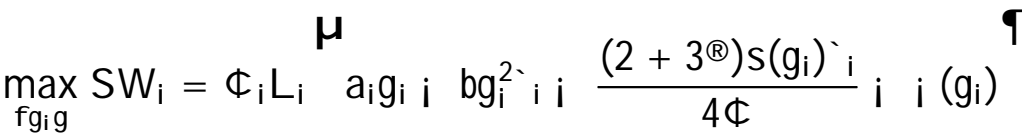

$$
\begin{aligned}
& \text { under the constraint of equality between regional pro..ts, }
\end{aligned}
$$

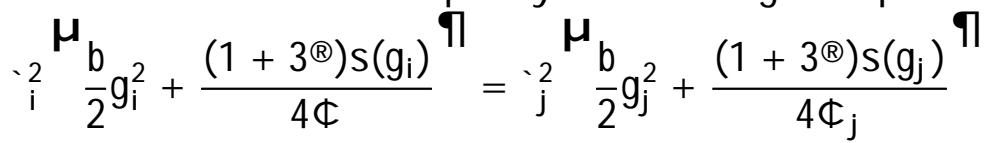

Denoting $B\left(g_{i}\right)=b g+\frac{\left(1+3 \otimes S^{0}\left(g_{i}\right)\right.}{4 \phi}$ and $A\left(g_{i}\right)=\frac{b}{2} g_{i}^{2}+\frac{(1+3 \otimes) s\left(g_{i}\right)}{4 \phi}$, the pro..t equalization condition between the two regions becomes:

$$
\frac{{ }_{A}}{{ }_{B}}=\frac{S}{A\left(g_{B}\right)}
$$

Moreover, the total number of ..rms $N$ is given by $N=n_{A}+n_{B}$. Hence the relationship:

$$
\frac{\Phi L_{A}}{A}+\frac{\$ L_{B}}{B}=N
$$

From this, we get that each ..rm in region $i$ employs ${ }_{i}$ workers with ${ }_{i}=\frac{\phi L_{i}}{N}+\frac{\phi L_{j}}{N} \quad \frac{q}{\frac{A\left(g_{j}\right)}{A\left(g_{i}\right)}}$. Then we can derive how this employment pool of a ..rm in region $\mathrm{i}$ is axected by the level of general human capital in that region:

$$
\frac{@_{i}}{@_{i}}=i \frac{\phi L_{j} B\left(g_{i}\right)}{2 N A\left(g_{j}\right)} \frac{S}{A(g)}
$$

Clearly when the productivity exect ( resp. $\neq$ exibility exect) dominates, $B\left(g_{i}\right)$ is positive (resp. negative) and an increase in the level of general human capital $\mathrm{g}$ in region i decreases (increases) the size of the employment pool of a ..rm in that region. This is because an increase in $\mathrm{g}$ makes ..rms more (resp. less) willing to be located in region $\mathrm{i}$.

A fter computations, the ..rst order condition of each local government i writes as

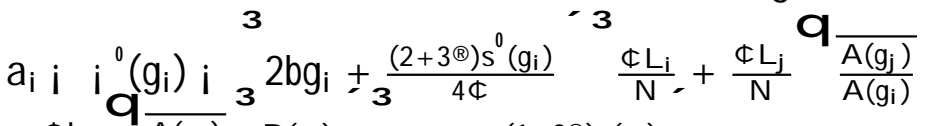

$$
\begin{aligned}
& +\frac{\Phi L_{j}}{2 N} \quad \frac{\overline{A\left(g_{j}\right)}}{A\left(g_{i}\right)} \frac{B\left(g_{i}\right)}{A\left(g_{i}\right)} \quad b_{i}^{2}+\frac{(1+3 \otimes) s\left(g_{i}\right)}{4 \nsubseteq}=0
\end{aligned}
$$

This equation de..nes implicitly the best response function $g=R_{i}(g)$ of government i to the level of general human capital chosen by the other region. Obviously, solving a system of two equations like ( $4: 2)$ and determining the asymmetric Nash equilibria $f g_{A}^{\alpha} ; g_{B}^{\text {a }} g$ is analytically intractable. However when the two regions are slightly asymmetric and that ®is close to 0, we are able to provide some insights of the impact of asymmetric integration.

\footnotetext{
${ }^{14}$ Thisse and Zenou (1996) ..nd optimal to have ${ }^{\circledR}{ }^{\prime} \quad 0$ in order to maximize net expected wages in an isolated region.
} 


\subsection{Integration between regions of dixerent size}

Consider ..rst that the two regions $A$ and $B$ only dixer in size with $L_{A}>L_{B}$. Also, in order to have a benchmark before integration, suppose that when there is no integration, the number of ..rms in each region is proportional to the size of the region (i.e. $\frac{L_{a}}{n_{a}}=\frac{L_{b}}{n_{b}}$ ). Then it is easy to see that although they have dixerent sizes, the two regions will make the same general human capital choice. As a matter of fact, the employment pool of each ..rm is the same in each region, hence the maximization program of the local government in each region is also the same ${ }^{15}$. Given that ${ }^{\circledR}$ is close to 0 , the two local governments then choose ge such that:

$$
a_{i} i^{0}\left(g_{c}^{a}\right) i{ }^{\mu}{\frac{2 \phi L_{i}}{n_{i}}}^{\text {I } \mu} b_{c}^{a}+{\frac{s^{0}\left(g_{c}^{a}\right)}{4 \phi}}^{\text {व }}, 0 ; 8 i=A ; B
$$

Note that under our assumption of proportionality between the initial number of ..rms and the size of the region, pro.ts and wages before integration are also the same in the two regions. This provides therefore a useful benchmark to compare with what happens after integration.

Consider now that ..rms can be located in the region they wish. Then the ..rst order condition (4:2) giving the optimal choice of general human capital of each region collapses to:

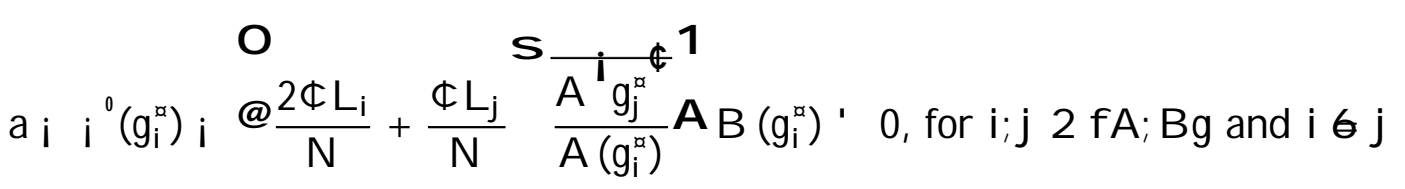

We have then the following proposition.

Proposition 6 . Let the two regions $A$ and $B$ dixer only by their size with $L_{A}=L+">$ $L_{B}=L_{i}$ ": Then

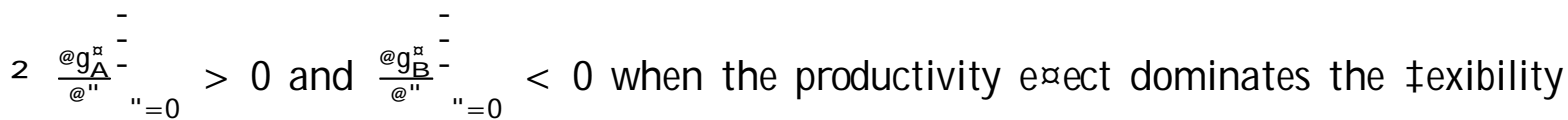
exect.

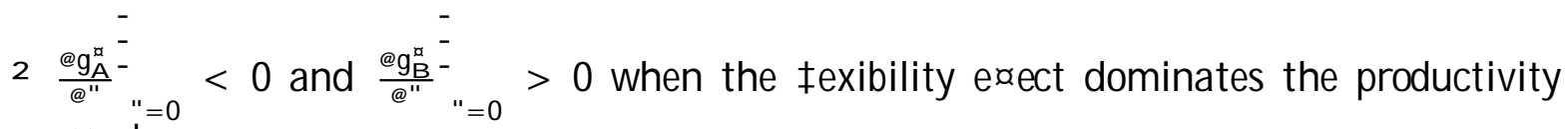
exect.

2 In both cases $\frac{\Theta_{A}}{\Theta^{i}}=0$

P roof. See the appendix.

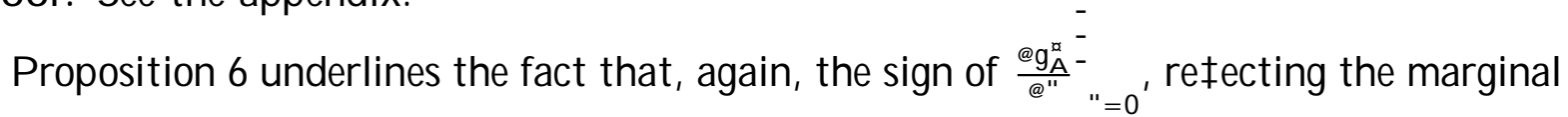
deviation of the asymmetric integration case from the symmetric integration case, depends on the relative weight of the productivity and ‡exibility exects. More precisely, when the productivity exect dominates, the small region $B$ tends to spend more on general human capital, while on the contrary, when the $\ddagger$ exibility exect is dominant, it is the larger region $A$

\footnotetext{
${ }^{15}$ See proposition 2 giving the optimal level of general human capital $g_{c}^{a}$ in a non integrated region.
} 
which has an incentive to provide more general human capital. Also, the number of workers employed per ..rm (the size of the local pool of workers of a ..rm) is increased in the large region and is smaller in the small region. In other words, ..rms localized in the bigger region employ more workers than ..rms installed in the small region. Finally, the total number $\mathrm{n}_{\mathrm{A}}$ of ..rms localized in the large region $A$ increases but less than proportionally with the size of that region.

The intuition for these results is the following. The employment pool of a representative ..rm is larger in the large region than in the small one. Therefore competition between ..rms in the labor market is less intense in the large region than in the small one, providing an advantage in terms of ..rms' localization for the larger region.

When the productivity exect dominates, ..rms prefer to be localized in the region with the population best endowed with general education. This induces local governments to spend more on general human capital after integration than before. Because of its size advantage in terms of ..rms localization, the large country can then axord to spend less in general human capital while, on the contrary, the small region needs to spend more to counteract its disadvantage. The total exect of integration is then an increase in general human capital with a stronger impact for the small region than for the large one.

Similarly when the $\ddagger$ exibility exect is dominant, local governments have an incentive to reduce their provision of general human capital to attract ..rms in their region. Hence the level of general education will tend to be smaller in both regions. However, because of its size advantage on the labor market, the large region can axord to invest more in general education without a risk to make too many ..rms go to the other region, while on the contrary, the small region needs to reduce even more its provision of general human capital to be able to attract ..rms from the other region. If regional integration axects negatively investment in general education in both regions, the exect is clearly stronger for the smaller region.

In conclusion, it appears that the small region is always more axected by integration (positively or negatively) than the large region. Given our benchmark before integration, this result suggests that asymmetric regional integration increases the divergence between small and large regions in wages and welfare.

\subsection{Integration between regions with dixerent productivities}

Let now the two regions $A$ and $B$ dixer only with their production technology ${ }^{16}$. Suppose more precisely that $a_{A}>a_{B}$. We keep also the assumption that $\mathbb{B}_{A}=\mathbb{B}_{B}{ }^{\prime} 0$.

The local governments' choice of general human capital are given by the following condition, $8 \mathrm{i} ; \mathrm{j}=\mathrm{A}$; $\mathrm{B}$ :

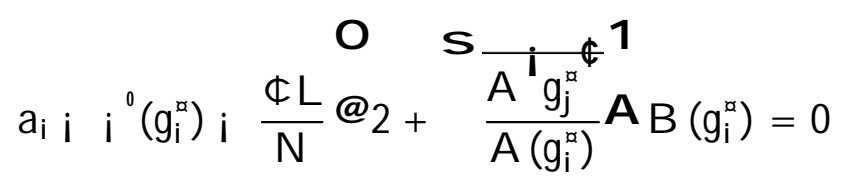

Then the following proposition characterizes the marginal impact of asymmetric integration:

\footnotetext{
${ }^{16} \mathrm{~T}$ his regional speci..city in production technologies may come from dixerences in the level of infrastructure equipments between the two regions.
} 
Proposition 7. Let regions $A$ and $B$ dixer by their productivity parameters: $a_{A}=a+{ }^{\prime}$

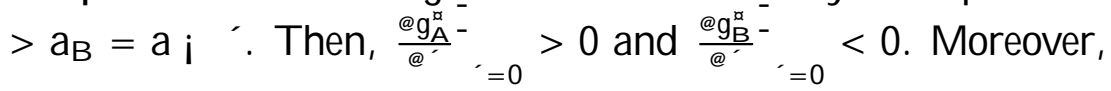

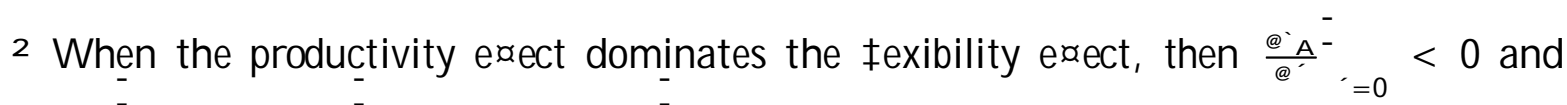

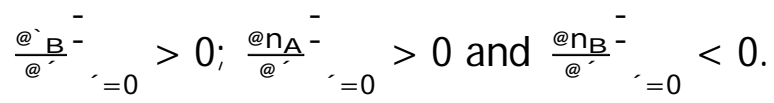

2 When the fexibility exect dominates the productivity exect, then ${\frac{\Phi_{A}}{\Theta^{-}}}_{=}^{-}=0$

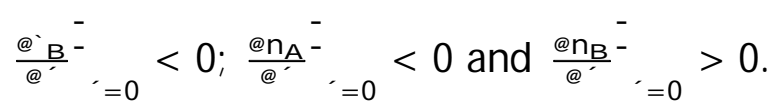

Proof. See the appendix.

Proposition 7 shows that the region with the higher (smaller) productivity is ready to provide more (less) general human capital than in the symmetric integration case. The reason is that the region with the higher productivity level pays higher wages per unit of ed cient labor. Hence the marginal return to general human capital is larger in this region. The exects on ${ }_{A} A$ and ${ }_{B}$; the employment pool per ..rm in regions $A$ and $B$; and on $n_{A}$ and $n_{B}$, the number of ..rms in regions $A$ and $B$, depend then, in turn, on the relative importance of the productivity and $\ddagger$ exibility exects. Clearly, when the productivity exect dominates the $\neq$ exibility exect, ..rms' pro..ts depend positively on the general human capital level of the region. As the high productivity region A provides more general education, ...rms have higher incentives to locate in this region, leading to a higher ..nal number of ..rms $n_{A}$ and a smaller employment pool per ..rm I $I_{A}$ : Conversely, when the $\ddagger$ exibility exect outweighs the productivity exect, ..rms' pro..ts depend negatively on general human capital and the large region A spends more on general human capital. Thus less ..rms get localized in A and the employment pool of workers per ..rm in that region is larger.

\section{Conclusion}

In this paper, we have investigated the impact of regional integration, in the sense of ..rms' regional mobility, on the incentives for local governments to invest in education. A crucial feature of the analysis has been to recognize that human capital is characterized by two dimensions. Horizontally, individuals can be dixerentiated by speci..c skills which do not necessarily match the speci..c skills required by the ..rms' technologies. This induces therefore the need for some speci..c training.

Vertically, the general human capital dimension has two important aspects. First, for an individual who has acquired the speci..c skill required by a ..rm's technology, a higher level of general human capital increases the productivity of the worker on the job. This is the productivity exect of general education. Second, general human capital also provides a higher ‡exibility in learning, therefore reducing the cost of training to acquire a speci..c horizontal skill. This is the fexibility exect of general education. While the productivity exect is bene..cial to both workers and ..rms, the $\ddagger$ exibility exect, by increasing the competition between ..rms in the labor market, is advantageous only to workers. 
In this context, we emphasized that the impact of regional integration on local governments educational policies depends crucially on the relative importance of the two exects. In the case of symmetric regions, we showed that regional integration induces local governments to overinvest (reps. underinvest) in general human capital when the productivity ( resp. ‡exibility) exect dominates. Consequently, immobile workers tend to bene.t from regional integration when general human capital generates strong productivity exects. On the other hand, workers ultimately loose when general education provides important ‡exibility capacities in the local labor market.

When the two regions are slightly dixerent in size, we also show that the small region is more sensitive than the large region in its choice of local educational policy when there is regional integration.

F inally when the two regions dixer slightly in terms of the et ciency of their production systems, the more ed cient region tends to invest more in general human capital than the less et cient one. A gain the resulting impact on the regional localization of ..rms depends on the relative importance of the productivity and $\ddagger$ exibility exects.

\section{A nnexe}

Proof of proposition 3.

We want to show that $\frac{\Theta_{1}^{n}}{\Theta^{R}}>0$ : Note ..rst that if this inequality is veri..ed when the fexibility exect dominates the productivity exect, then it is still veri..ed in the opposite case. Thus it is suç cient, to prove it when the $\ddagger$ exibility exect dominates.

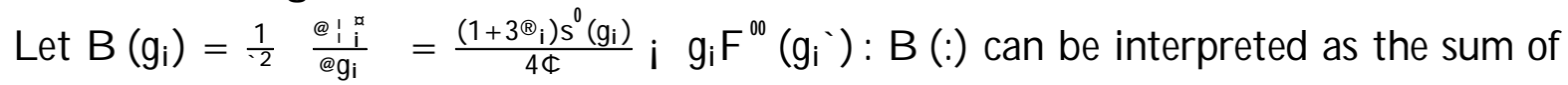
the productivity and $\ddagger$ exibility exects. Thus $B(:)$ is positive when the productivity exect outweighs the $\ddagger$ exibility exect. $\mathrm{B}(:)$ is increasing in $\mathrm{g}$ under the suc cient hypothesis that $\mathrm{F}^{\infty}(:)$ is negative $\mathrm{e}^{17}$.

Equation (3:5) can thus be rewritten as follows:

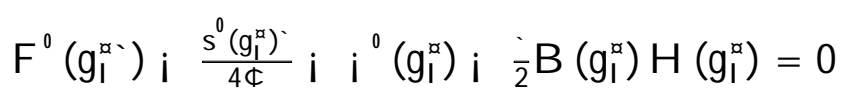

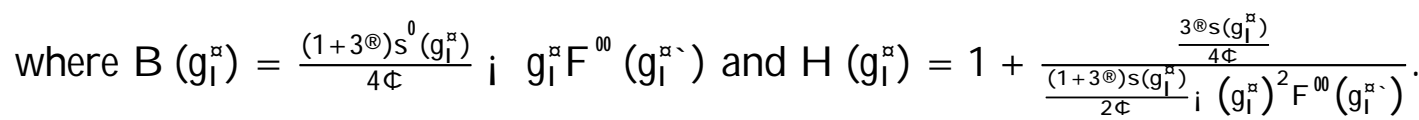

Dixerentiating this equation gives:

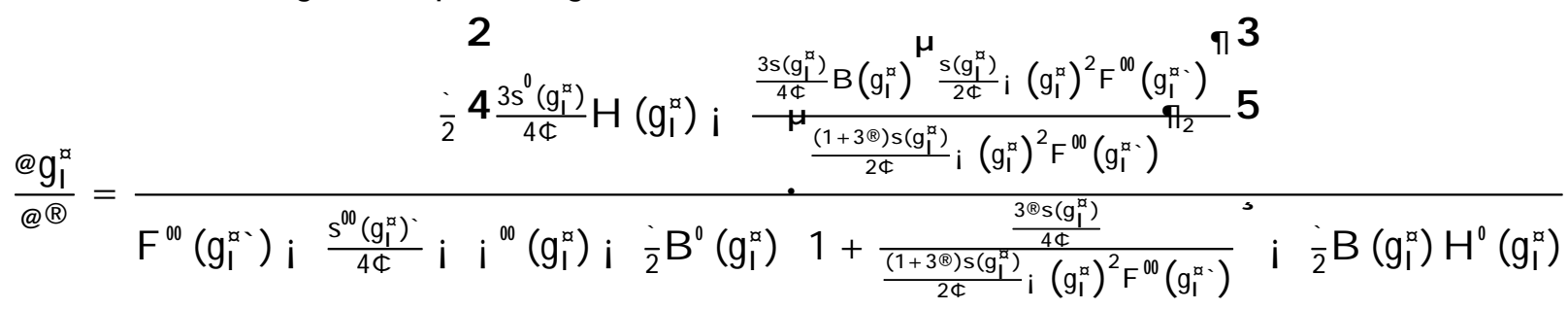

\footnotetext{
${ }^{17} \mathrm{~T}$ his hypothesis is veri..ed when the production function is quadratic.
} 


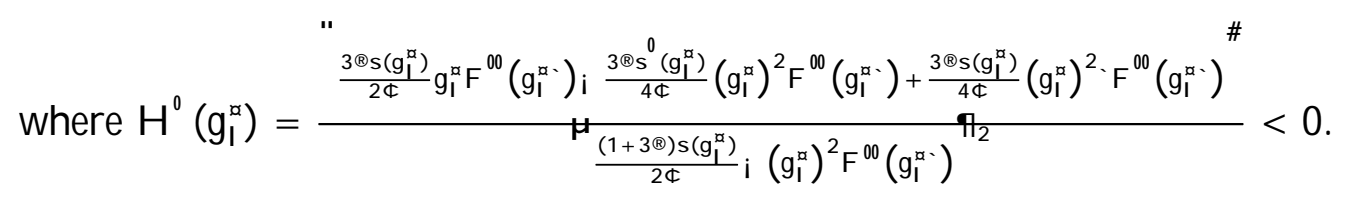

When $B\left(g_{i}^{a}\right)<0$ (the $\ddagger$ exi bility exect outweighs the productivity exect), the denominator and the numerator are both negative at the equilibrium. Hence $\frac{\varrho^{n}}{\varrho_{B}^{*}}>0$ :

\section{Proof of proposition 4.}

Note that $F^{0}\left(g^{\prime}\right)$ i $\frac{s^{0}(g)^{\prime}}{4 c} i i^{0}(g)$ is decreasing in general human capital, while $B(g)$ is an increasing function ${ }^{18}$. Consequently, if the productivity exect outweighs the $\ddagger$ exibility exect when the region are isolated, then it is still veri..ed when the regions are integrated. $B\left(g_{c}^{a}\right)$ and $B\left(g_{1}^{\mathrm{g}}\right)$ have thus the same sign. Moreover, the curves $B(g)$ and $\frac{B(g) H(g)}{2}$ are crossing

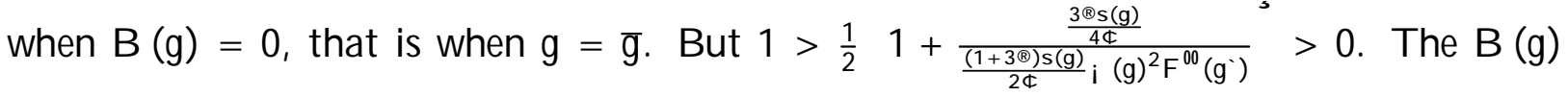
curve is thus more sloping than the $\frac{\mathrm{B}(\mathrm{g}) \mathrm{H}(\mathrm{g})}{2}$ curve.

This means that, when the $\ddagger$ exibility exect dominates the productivity exect, then the curve $F^{0}\left(g^{\prime}\right)$ i $\frac{s^{0}(g)^{\prime}}{4 \phi} i i^{0}(g)$ crosses the curve $\frac{{ }^{\circ} B(g) H(g)}{2}$ before the curve ${ }^{`} B(g)$. Consequently $g^{a}<g_{c}^{a}$. But the $\neq$ exibility exect dominates the productivity exect if $g_{c}^{a}<g$, that is if $F^{0}\left(g^{\prime}\right)$; $\frac{s^{0}(g)^{\prime}}{4 \phi} i i^{0}(g)<0$. Under the condition $F^{0}\left(g^{\prime}\right)$ i $\frac{s^{0}(g)^{0}}{4 \phi} i i^{0}(g)<0$; we get thus $g^{a}<g_{c}^{a x}$.

The equilibrium wage is increasing in general human capital, which gives $w_{1}^{a}<w_{c}^{a}$. Intra-regional wage inequalities depend negatively on the level of human capital publicly provided by the local government. Hence $V_{1}^{\mathbb{a}}>V_{c}^{a}$ :

Inversely, when the productivity exect outweighs the $\ddagger$ exibility exect, all the results are reversed.

\section{Proof of proposition 6 .}

We want to determine the impact of an increase in " on local educational pplicy choices. Dixerentiating the following equation, $a_{i} i^{0}\left(g_{A}^{\alpha}\right) i \frac{2 \phi(L+")}{N}+\frac{\Phi\left(L_{i} "\right)}{N} \quad \frac{A\left(g_{B}^{\alpha}\right)}{A\left(g_{A}^{\alpha}\right)} \quad B\left(g_{A}^{\alpha}\right)=0$, with respect to " in " $=0$, gives the following result:

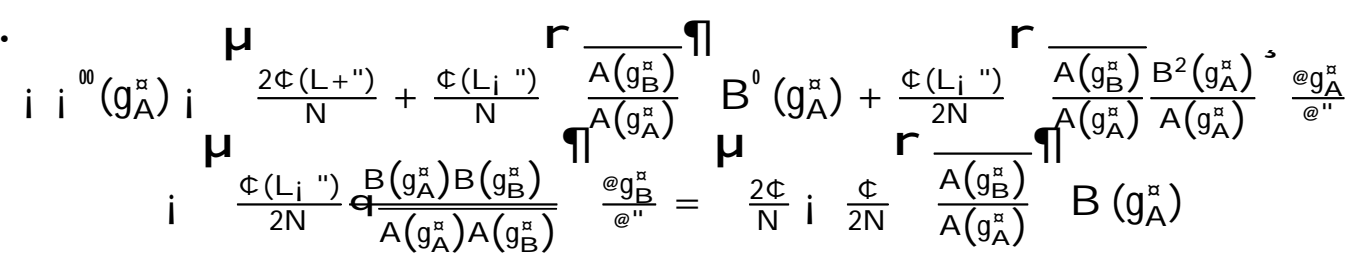

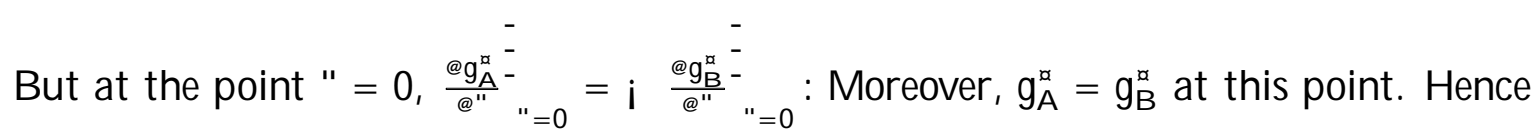

\footnotetext{
${ }^{18} \mathrm{Under}$ the suc cient hypothesis that $\mathrm{F}^{\infty}{ }^{\infty}(:)$ is negative.
} 


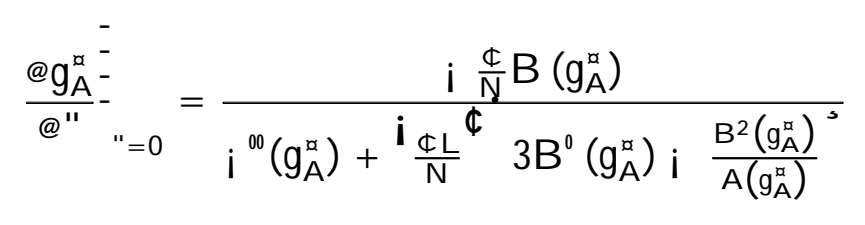

Now $2 B^{0}\left(g_{1}^{a}\right) A\left(g^{a}\right)$; $B^{2}\left(g_{1}^{a}\right)>0$; under the hypothesis that $s^{\infty}(:)=0$. Indeed, dixerentiating with respect to $\mathrm{g}$ shows that this function is constant. M oreover, in $\mathrm{g}=\mathrm{h}_{\mathrm{h}}{ }^{1} \frac{1}{4 \mathrm{~b} \mathrm{~b}}$, the function is positive. It follows that the denominator is positive. Hence, sign ${\frac{\mathbb{Q}_{A}^{x}}{\varrho^{n}}}_{n=0}^{-}=$

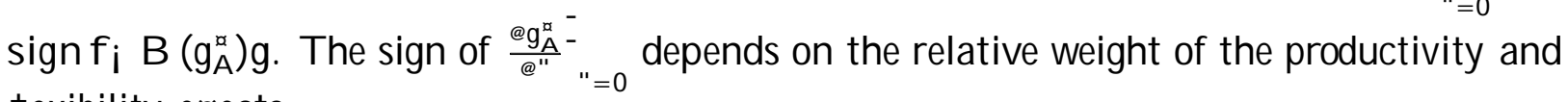
‡exibility exects.

The number of workers employed per ..rm in region $A$ is ${ }^{{ }_{A}}=\frac{\Phi(L+")}{N}+\frac{\Phi\left(L_{i}{ }^{\prime \prime}\right)}{N} \frac{r\left(g_{B}^{\pi}\right)}{A\left(g_{A}^{R}\right)}$. Dixerentiating ${ }^{\prime}$ with respect to " in " $=0$ gives:

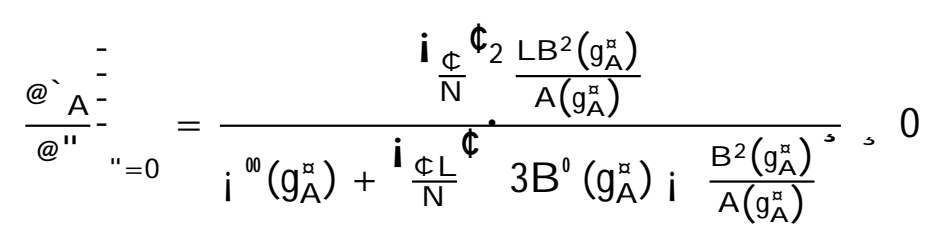

Thus the number of workers per ..rm is increased in region A and smaller in region $B$.

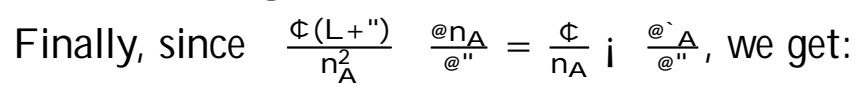

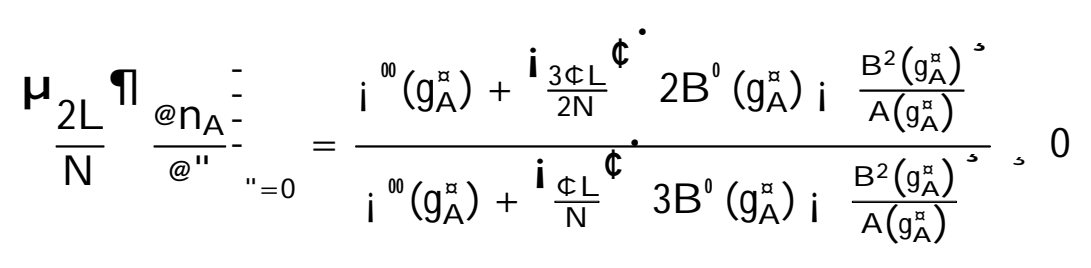

Hence the total number $n_{A}$ of ..rms localized in the large region $A$ increases but less than proportionally with the size of that region.

\section{Proof of proposition 7}

We want to determine the impact of an increase in ' on Jpcal educational policy choices. Dixerentiating the following equation, $a+{ }^{\prime} i i^{0}\left(g_{A}^{\alpha}\right) ; \frac{\phi L}{N} 2+\frac{\overline{A\left(g_{B}^{\alpha}\right)}}{A\left(g_{A}^{\alpha}\right)} B\left(g_{A}^{\alpha}\right)=0$, with respect to ' in ' $=0$, gives the following result:

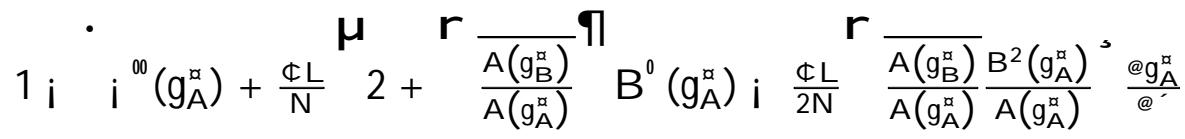

$$
\begin{aligned}
& \text { i } \frac{c L}{2 N} \frac{B\left(g_{A}^{\alpha}\right) B\left(g_{B}^{\alpha}\right)}{A\left(g_{A}^{\alpha}\right) A\left(g_{B}^{\alpha}\right)} \frac{@_{B}^{\alpha}}{\Theta}=0
\end{aligned}
$$




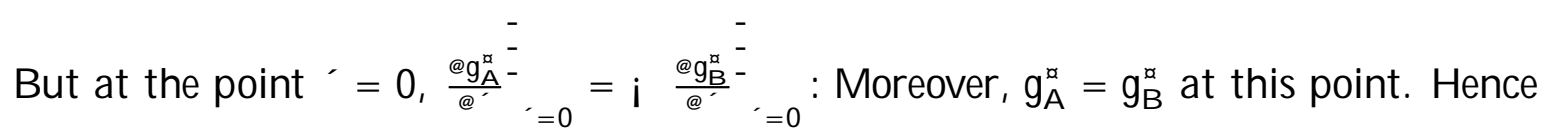

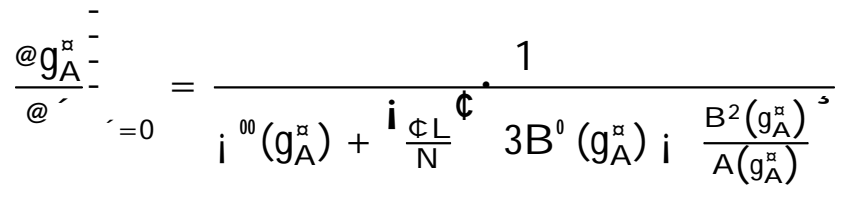

Now $2 B^{0}\left(g_{A B}^{\alpha}\right) A\left(g_{A B}^{\alpha}\right) ; B^{2}\left(g_{A B}^{\alpha}\right)>0$. Thus $\frac{\varrho_{A}^{\alpha}-}{@},=0$

\section{R eferences}

[1] Becker G. (1964) Human Capital, Columbia University Press.

[2] B ucovetsky S. (1991), « A symmetric Tax Competition », J ournal of U rban E conomics, $21,333-350$.

[3] Hashimoto M. (1981) « Firm Speci..c Human Capital as a Shared Investment », American Economic Review, 71, 475-482.

[4] J ellal M., Thisse J .-F. and Zenou Y. (1997) « Demand Uncertainty, Mismatch and (Un)employment », mimeo CORE.

[5] J ovanovic B. (1979a) « J ob M atching and the Theory of Turnover » , J ournal of P olitical E conomy, 87, 972-990.

[6] J ovanovic B. (1979b) « Firm Speci..c Capital and the Theory of Turnover », J ournal of Political Economy, 87, 1246-1260.

[7] Kennan J . and Riezman R. (1988) « Do big countries win tarix wars? », International Economic Review, 29, 81-85.

[8] K im S. (1989), « Labor Specialization and the Extent of the Market », J ournal of Political E conomy, 97, 692-705.

[9] K remer M. (1993) « The O-Ring Theory of E conomic Development », Quarterly J ournal of Economics, 108, 551-576.

[10] Mieszkowski P. and Zodrow G. (1986) « Pigou, Tiebout, Property Taxation, and the Underprovision of Local Public Goods », J ournal of Urban Economics, 19, 356-370.

[11] OECD (1998) Education at a glance: OECD Indicators.

[12] Salop S. (1979) « Monopolistic Competition with Outside Goods », Bell J ournal of E conomics, 10, 141-156.

[13] Stevens M. (1994) «A theoretical model of on-the-job training with imperfect competition », Oxford E conomic Papers, 46, 537-562. 
[14] Thisse J .-F . and Zenou Y. (1995) « A ppariement et concurrence spatiale sur le marché du travail », Revue Economique, 46, 615-624.

[15] Thisse J.-F. and Zenou Y. (1996) « How to ..nance education when the labor force is heterogeneous? », mimeo CORE.

[16] Wildasin D. (1988) « Nash Equilibria in Models of Fiscal Competition », J ournal of P ublic E conomics, 35, 229-240.

[17] Wildasin D. (1989) « Interjuridictional Capital Mobility: Fiscal Externality and a Corrective Subsidy », J ournal of Urban E conomics, 25, 193-212.

[18] Wilson J. (1986) « A Theory of Interregional Tax competition », J ournal of Urban E conomics, 19, 296-315.

[19] Wilson J . (1991) « Tax competition with Interregional Dixerences in Factor Endowments », Regional Science and urban Economics, 21, 423-451. 